\title{
Climate Contributions and the Paris Agreement: Fairness and Equity in a Bottom-Up Architecture Nicholas Chan
}

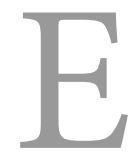

thical questions of fairness, responsibility, and burden-sharing have always been central to the international politics of climate change and efforts to construct an effective intergovernmental response to this problem. The conclusion of the Paris Agreement last December, lauded by the media, governments, and civil society around the world, is the most recent such effort, following the collapse of negotiations six years prior at the 2009 Copenhagen conference. The shape and form of the Paris Agreement, however, represents a radically different governance structure to its predecessor, the Kyoto Protocol, reorienting the international regime toward a "bottom-up" structure, emphasizing national flexibility in order to ensure broader participation. In doing so, the Paris Agreement also provides a different answer to the question of what constitutes a fair and equitable response to climate change.

The purpose of this essay is to review the normative implications of the Paris Agreement, namely in the challenges it poses for attaining a fair distribution of the "carbon budget" and for maintaining a good chance of keeping global warming below 2 degrees Celsius by the end of the century. In these new institutional arrangements and political compromises that have set the framework for climate action in the coming decade and beyond, how will fairness and equity be ensured in a world of voluntary climate "contributions"? The first section of this essay presents the key features of the Paris Agreement in the context of the "top-down/bottom-up" discussion on governance architectures and the notion of a carbon budget that has framed much of the recent ethics-based discussion on the distribution of emission rights and responsibilities. The second section then highlights the new ways in which the Paris Agreement has sought to respond to the normative importance of equity considerations in the climate response,

Ethics \& International Affairs, 30, no. 3 (2016), pp. 291-301.

(c) 2016 Carnegie Council for Ethics in International Affairs

doi:10.1017/So892679416000228 
namely, in its accommodation of "national circumstances" as a context for fairness. Finally, this essay points to the more positive implications of this emphasis on national circumstances-particularly regarding the new opportunities for argumentation and social scrutiny that claims of being "fair" and "ambitious" are subject to that will need to be used to ensure that the new climate architecture delivers on its promise.

\section{The Paris Agreement and Carbon Budgets in a Bottom-up Architecture}

After four years of intergovernmental preparatory meetings, countries adopted the Paris Agreement by consensus at the 21st Conference of the Parties of the UN Framework Convention on Climate Change (UNFCCC). At its heart is a commitment by all countries to submit a "nationally determined contribution" to the global effort to address climate change over the 2020-2030 decade-especially, but not exclusively, in terms of emissions reduction. ${ }^{1}$ Over the course of 2015 , countries had submitted indicative contributions, referred to as "intended nationally determined contributions" (INDCs), which had been estimated to lead to no less than 2.7 degrees Celsius of global warming by the end of the century-well above the 2 degrees Celsius that had been the agreed target since the ill-fated Copenhagen conference. ${ }^{2}$

INDCs (or simply NDCs, once they are formally communicated by countries upon ratifying the Paris Agreement) took a range of forms. Some countries submitted pledges to reduce emissions against a business-as-usual baseline; others to reduce their emission intensity (of greenhouse gas emissions per unit of GDP); and others to make absolute net reductions in emissions. By the close of the conference, almost every country in the world had made such a submission, and this broad participation is widely seen as one of the Paris Agreement's major achievements. Another major achievement was the collective reaffirmation of the below-2-degrees-Celsius target previously set out in Copenhagen; and for the first time, incorporation of the more aspirational goal of "pursuing efforts" to keep warming to below 1.5 degrees Celsius, responding to a demand made by island states, African countries, and other vulnerable nations since Copenhagen. ${ }^{3}$

One of the key features of the INDCs, as their name suggests, is their nationally determined character: that is, their content will be the decision of states alone, and not subject to international negotiation or revision. They will be "contributions," and not "commitments," a much softer version of the language traditionally used 
in such international treaty processes. ${ }^{4}$ Taken cumulatively, the INDCs are what best epitomize the overall character of the new bottom-up approach to climate governance embedded in the Paris Agreement.

This design can be best understood through a comparison to the last legally binding international agreement on climate change, the 1997 Kyoto Protocol, and by examining the ensuing discussions about the appropriate institutional "architecture" to govern the global response to climate change, particularly surrounding the 2009 Copenhagen conference. ${ }^{5}$ The Kyoto Protocol's quantified targets to reduce emissions were subject to negotiation, with both their character (legally binding, economy-wide absolute reductions) and timetables established at the international level. They included strong rules on how to account for emissions and report progress, and an international mechanism for compliance. ${ }^{6}$ In these waysalthough imperfectly so-the Kyoto Protocol represents the "top-down" architectural model for climate cooperation, ${ }^{7}$ embodying a particular understanding of fairness in the differentiation of its targets, with only developed countries taking on quantified emission reduction obligations. ${ }^{8}$

By contrast, in most respects (with the exception of the below-2-degrees temperature target), the Paris Agreement constitutes a turn toward a bottom-up architecture whereby explicit international coordination is eschewed in favor of increased national flexibility. Countries have the latitude to make their own pledges, determining both their character and timing, with an emphasis on facilitative transparency rather than on punitive compliance. The Paris Agreement as a whole is legally binding, but the quantitative pledges themselves are not.

Where does this evolution in the governance structure of the international regime leave efforts to ensure an equitable response to climate change? The important point for this analysis is that ethical considerations for the international distribution of emission mitigation responsibilities have often assumed a topdown architecture. One particular fact has loomed large over the myriad proposals that have been made concerning fairness and justice in global mitigation efforts: if humanity is to stand a likely chance of meeting the goal of below 2 degrees, the cumulative amount of carbon emitted into the atmosphere must be limited to below one trillion tons of carbon since industrialization began, of which more than half has already been emitted..$^{9}$ In other words, there is a quantified amount of carbon that can be emitted, a quantity that decreases further still if the aspiration of below 1.5 degrees is to be met. ${ }^{10}$ As a result, the efforts described above 
have often focused on the idea of a carbon budget, with one major challenge being how to distribute this budget fairly. ${ }^{11}$

Some scholars have focused on what are the appropriate moral principles and perspectives on which to base such distributions. ${ }^{12}$ Others, meanwhile, have proceeded to put these in quantitative terms, calculating precise carbon budgets for individual countries, each in terms of its "fair share," generally based on a balance of a country's historical responsibility for emissions and its capacity to reduce emissions given development needs. ${ }^{13}$ The general logic in this regard is to begin with the desired temperature goal, calculate the remaining carbon budget, establish principles (moral or otherwise) on how to distribute the budget, and then calculate each country's share accordingly. Of course, each analysis along these lines also offers a different definition of how to specify each of the criteria that contribute to these budgets, resulting in a further diversity of proposed budget allocations. ${ }^{14}$ But what all these different analyses have in common is that they all assume that such distribution is both desirable and possible, and that such apportioning to reach a fair share can be done through top-down coordination at the international level.

By contrast, all the Paris Agreement does in this respect is entrench the desired temperature goal of below 2 degrees Celsius (and its more ambitious aspiration of below 1.5 degrees Celsius). There has been no agreement on the size of the budget, on principles to distribute it, or on what each country's fair share should be. Indeed, there has been no agreement on the very notion of a budget itself, as illustrated by former UNFCCC Executive Secretary Christiana Figueres's comment that "politically [carbon budgets] would be too difficult." ${ }^{15}$ Developed countries will generally continue to "take the lead," and in other aspects, particularly on climate finance to support both mitigation and adaptation, they still have specific obligations, ${ }^{16}$ but this is a far cry from the particular understanding of fairness embodied in the Kyoto Protocol. A sizeable "emissions gap" between current pledges and the trajectory of emission reductions needed to stay within the carbon budget still exists. ${ }^{17}$

\section{Whither Equity? The Rise of Nationally Determined Climate Fairness}

In place of a general bargain in which fairness is chiefly reflected in the differentiation of commitments, the Paris Agreement's expression of fairness and equity 
represents the new preference for bottom-up flexibility. The issue of how fairness is to be safeguarded in a bottom-up architecture has received relatively little explicit attention, ${ }^{18}$ with most justifications emphasizing political participation and efficiency as its key benefits. Instead, the key provision in the Paris Agreement architecture is a requirement that states themselves justify the fairness and "ambition" of their own contributions.

In preparation for the Paris summit, countries agreed at the preceding conference in Lima, Peru, in 2014, on procedures for submitting INDCs prior to Paris. Among the criteria for submitting an INDC was the specification that it would indicate how it is considered "fair and ambitious, in light of its national circumstances, and how it contributes towards achieving the objective of the Convention as set out in its Article 2." ${ }^{\prime 19}$ This represents something of an innovation in treaty design, where the fairness of individual commitments is usually implicitly reached through the process of negotiation and the resulting differentiation of responsibilities, rather than explicitly articulated. ${ }^{20}$ While this exercise in self-assessment and self-justification of fairness is also an acknowledgement of the continuing normative pull of fairness in the climate regime (as indicated by the fact that almost all countries met this requirement, despite its nonbinding character ${ }^{21}$ ), the result has inevitably been partly an instrumental exercise. ${ }^{22}$ From no country has there been or will there be acknowledgement that its contribution is unfair or unambitious, or that it does not appropriately contribute to achieving the objective of the Framework Convention. Nonetheless, the cumulative result of almost every country detailing its self-perception of fairness highlights the degree to which principles of fairness receive widespread support, even if convergence on such principles is viewed as impossible. The synthesis report prepared by the UNFCCC secretariat, taking stock of INDCs submitted up to the end of April 2016, reflected this diversity of criteria in terms of fairness, which included "responsibility and capability; share of emissions; development and/or technological capacity; mitigation potential; cost of mitigation actions; the degree of progression or stretching beyond the current level of effort; and the link to objectives and global goals." ${ }^{23}$

At the same time, the report also highlighted the view that convergence on the specific combination of principles and criteria is impossible: "no single indicator can accurately reflect fairness or a globally equitable distribution of Parties' efforts." ${ }^{24}$ A number of examples illustrate the diversity of these conceptions of fairness. ${ }^{25}$ The United States declares that its "fair and ambitious ... action to achieve 
the 2025 target represents a substantial acceleration of the current pace" of emission reductions. ${ }^{26}$ The European Union's target “represents a significant progression beyond its current undertaking . . . consistent with the need for at least halving global emissions by 2050 compared to 1990." 27 South Africa, among a handful of countries that do express their INDC in terms of a carbon budget, justifies its mitigation pledge being less than what its share of the global carbon budget might allow, and it also points to the "significant rigidity in its economy," noting that "any policy-driven transition to a low-carbon and climate resilient society must take into account and emphasize its overriding priority to address poverty and inequality." ${ }^{28}$ Australia asserts that its contribution constitutes a "significant progression" beyond its previous target for 2020, noting that it "is comparable to the targets of other advanced economies" and "takes account of Australia's unique national circumstances, including [its] role as a leading global resources provider ... and higher than average abatement costs." 29

For India, "both in terms of cumulative global emissions (only 3\%) and per capita emissions ( $1.56 \mathrm{tCO}_{2} \mathrm{e}$ in 2010), [the country's] contribution to the problem of climate change is limited, but its actions are fair and ambitious. . . Efforts to avoid emissions during our development process are also tied to the availability and level of international financing and technology transfer, since India still faces complex developmental challenges." ${ }^{30}$ Meanwhile, Bangladesh cites its status as a Least Developed Country "whose emissions are less than $0.35 \%$ of global emissions" and notes that its "per capita [greenhouse gas] emissions will not exceed the average for developing countries." It further notes that the INDC "represents the first time that Bangladesh has made an undertaking to take action on mitigation." 31

What is notable in these discussions of climate fairness is that the different national circumstances of countries have now become paramount. The UNFCCC's synthesis report summarizes the wide range of circumstances cited by countries to justify the fairness of their contributions, including

the need for poverty eradication and the improvement of living standards; population structure and urban density; the impacts of local or regional conflicts; economic development and the current industrial structure (e.g., share of energy-intense or energy-efficient industries; or if it is a fossil fuel producing or exporting country); energy mix and related limitations; economic diversification processes; dependence on the global supply chain for food and energy security; sensitivity to the volatility of regional and global developments; the size and geography of the country; climatic conditions; natural resource endowment, including for renewable energy; and vulnerability to 
climate change impacts, including dependency on climate-sensitive sectors such as agriculture, tourism and water. ${ }^{32}$

In other words, in this bottom-up architecture, national circumstances have become the watchwords of fairness and ambition. Efforts and contributions are shaped not by fairness in the context of the science of the international carbon budget, but by fairness in the context of individual circumstances, or, as the secretariat put it, "National determination has enabled Parties to shape their efforts in line with their circumstances." ${ }^{33}$ Notably, the overall objective of the Paris Agreement is framed in the context of the long-standing principle of "common but different responsibilities and respective capabilities," but followed with a new, deeply fought-over qualifier: "in the light of different national circumstances." ${ }^{34}$

Before turning to other elements of how fairness is conceptualized in the Paris Agreement's architecture, it is important to note one important effect of contextualizing fairness in terms of national circumstances: the question of the actual distribution of emission responsibilities and obligations is absent from formal negotiations. The content of national contributions themselves is not the subject of negotiation; instead, much of the focus of dispute in the negotiating process leading up to the Paris Agreement was over the process by which countries would make these submissions. Thus, the other lauded elements of the Paris Agreement are process-related provisions intended to drive increasingly demanding pledges over time. Chief among these is a "global stocktake" in 2023 (the midpoint of the first five-year cycle of contributions) and increased transparency procedures to allow mutual understanding of the actions of others.

\section{Normative Argumentation in a Bottom-up World}

The Paris Agreement provides a global temperature goal, but avoids implementing the idea of a finite carbon budget, which critics say is a major limitation of the new treaty. On the positive side, however, the broader bottom-up orientation of the agreement opens new opportunities for normative debate on fairness and equity in national responses to climate change. The overarching rationale of the bottom-up architecture is that increasing national flexibility and discretion in determining climate contributions encourages broader participation. Broader participation, in turn, is supposed to support and encourage collective increases in the ambition of contributions. In this respect, at least, the Paris Agreement marks the 
emergence of a new norm and social expectation that INDCs should, in the words of the UNFCCC's 2014 Lima decision, "represent a progression beyond the current undertaking" of each country. ${ }^{35}$ As stated in the formal Agreement,

Each Party's successive nationally determined contribution will represent a progression beyond the Party's then current nationally determined contribution and reflect its highest possible ambition, reflecting its common but differentiated responsibilities and respective capabilities, in the light of different national circumstances. ${ }^{36}$

Beyond this new principle, however, what may be of more lasting importance is the social character of this nationally determined self-assessment of fairness provided in INDCs. In other words, these public claims of fairness are subject to contestation and argumentation in order to become socially accepted as being genuinely fair and ambitious. These assessments and arguments may necessarily be informal ones, ${ }^{37}$ but civil society actors are already undertaking such critiques at both the international and domestic level. One notable assessment, for instance, finds Russia's INDC representing a zero percent contribution to its fair share, the United States' INDC representing a one-fifth contribution of its fair share, Brazil's representing a two-thirds contribution, and, conversely, China's contribution actually exceeding its fair share. ${ }^{38}$

Indeed, countries may increasingly be starting to undertake similar critiques of each other's pledges, albeit in an informal manner. Brazil's environment minister, for instance, highlighted Singapore's and South Korea's INDCs as being “inexcusable" given their relative prosperity. ${ }^{39}$ And those countries that did not submit an INDC prior to the September 2015 deadline for the Paris conference were singled out as "climate laggards"-an indication of how the INDC submission has itself become a common measure of good international citizenship. ${ }^{40}$

Such critiques and public discussion over the social acceptance of the fairness claims made by a particular country may not on their own lead to a revision of that country's pledged contribution. But they do suggest the beginning of a different dynamic in the new bottom-up context of self-differentiation, where fairness and equity are discussed in terms of individual national contributions, rather than in terms of annexes or categories that divide countries simply into "developed" or "developing." Countries that may have previously been able to "hide" in these broad categories may find that they are no longer able to do so, and that they are subject to greater scrutiny than hitherto experienced and singled out for the quality and content of their national contributions. ${ }^{41}$ 


\section{ConClusion}

This essay has sought to draw out some of the ethical implications of the new bottom-up architecture embodied in the Paris Agreement on climate change. Further institutional arrangements, particularly in terms of transparency and reporting processes, and the new market mechanisms for carbon trading that have also been the subject of much moral analysis, are still to be developed in the interim few years before the Paris Agreement enters into force. What the Agreement has established, however, is an orientation toward bottom-up governance, whereby national flexibility extends to the way that fairness, equity, and ambition are considered. These themes are now explicitly contextualized by diverse national circumstances, providing countries with greater flexibility even as the world as a whole moves ever closer toward emitting the trillionth ton of carbon.

It is these institutional arrangements, and the prospects for achieving climate justice within them, that invite further scholarly engagement given the relative permanence that these arrangements will have for organizing climate action for the coming decade and beyond. While the discussion here has focused on the mitigation aspects in relation to fairness and the distribution of the carbon budget, the implications of the Paris Agreement's architecture for other elements of climate justice, especially in terms of fairness in adaptation responses and the rising prominence of "loss and damage" beyond the limits of adaptation, also deserve closer examination. ${ }^{42} \mathrm{~A}$ new conversation on how to safeguard the future is just beginning.

\section{NOTES}

${ }^{1}$ Some countries have expressed these in terms of an initial five-year period, up to 2025 .

${ }^{2}$ UNFCCC, "Synthesis report on the aggregate effect of the intended nationally determined contributions: an update," UNFCCC Doc. FCCC/CP/2016/2, May 2, 2016 (hereafter "INDC Synthesis Report"); UNFCCC, "Global Response to Climate Change Keeps Door Open to 2 Degree C Temperature Limit," October 30, 2015, newsroom.unfccc.int/unfccc-newsroom/indc-synthesis-report-press-release/.

3 Paris Agreement (Annex to Decision 1/CP.21, FCCC/CP/2015/10/Add.1) Article 2 (hereafter "Paris Agreement").

${ }^{4}$ Lavanya Rajamani, "Negotiating the 2015 Climate Agreement: Issues Relating to Legal Form and Nature," MAPS Research Paper 28 (2015).

5 Daniel Bodansky and Lavanya Rajamani, "The Evolution and Governance Architecture of the Climate Change Regime," January 15, 2015, papers.ssrn.com/sol3/papers.cfm?abstract_id=2168859.

${ }^{6}$ William Hare, Clare Stockwell, Christian Flaschland, and Sebastian Oberthür, "The Architecture of the Global Climate Regime: A Top-Down Perspective," Climate Policy 10, no. 6 (2010), pp. 600-614.

7 Daniel Bodansky and Eliot Diringer, "Evolution of the International Climate Effort," C2ES Brief, May 2014.

8 Jutta Brunnée and Charlotte Streck, "The UNFCCC As a Negotiation Forum: Toward Common but More Differentiated Responsibilities," Climate Policy 13, no. 5 (2013), pp. 589-607. 
9 Myles Allen et al., "Warming Caused by Cumulative Carbon Emissions Towards the Trillionth Tonne," Nature 458 (2009), pp. 1163-166; IPCC, "Summary for Policymakers," in Thomas Stocker et al., "Climate Change 2013: The Physical Science Basis: Contribution of Working Group I to the Fifth Assessment Report of the Intergovernmental Panel on Climate Change," Cambridge (2013), p. 27. See also www.trillionthtonne.org.

${ }^{10}$ INDC Synthesis Report, p. 52 and p. 56.

${ }_{11}$ Although some eschew the carbon budget as the framing concept for climate equity and fairness; see Sonja Klinsky et al., Building Climate Equity: Creating a New Approach from the Ground Up (Washington, D.C.: World Resources Institute, 2015).

${ }^{12}$ Henry Shue, "Human Rights, Climate Change, and the Trillionth Ton," in Denis G. Arnold, ed., The Ethics of Global Climate Change (Cambridge: Cambridge University Press, 2011); Darryl Moellendorf, "Treaty Norms and Climate Change Mitigation," Ethics \& International Affairs 23, no. 3 (2009); Marco Grasso, "Sharing the Emission Budget," Political Studies 60, no. 3 (2012), Simon Caney, "Justice and the Distribution of Greenhouse Gas Emissions," Journal of Global Ethics 5, no. 2 (2009).

${ }^{13}$ Renaud Gignac and H. Damon Matthews, "Allocating a $2{ }^{\circ} \mathrm{C}$ Cumulative Carbon Budget to Countries," Environmental Research Letters 10, no. 7 (2015); Michael R. Raupach et al., "Sharing a Quota on Cumulative Carbon Emissions," Nature Climate Change 4 (2014); Harald Winkler, T. Letete, and Andrew Marquand, "Equitable Access to Sustainable Development: Operationalizing Key Criteria," Climate Policy 13, no. 4 (2013); Paul Baer et al., "The Greenhouse Development Rights Framework," Heinrich-Böll-Stiftung (2008).

${ }^{14}$ Climate Action Tracker, "Are Governments Doing Their Fair Share? New Method Assesses Climate Action," March 27, 2015; Mathias Friman and Mattias Hjerpe, "Agreement, Significance, and Understandings of Historical Responsibility in Climate Change Negotiations," Climate Policy 15, no. 3 (2015); Benito Müller, Niklas Höhne, and Christian Ellermann, "Differentiating (Historic) Responsibilities for Climate Change," Climate Policy 9, no. 6 (2009).

15 Fiona Harvey, "IPCC's 'Carbon Budget' Will Not Drive Warsaw Talks, Says Christiana Figueres," October 24, 2013, www.theguardian.com/environment/2013/oct/24/ipcc-carbon-budget-warsaw-cli mate-change-christiana-figueres.

${ }^{16}$ Wolfgang Obergassel et al., "Phoenix from the Ashes: An Analysis of the Paris Agreement to the United Nations Framework Convention on Climate Change," Wuppertal Institute for Climate, Environment and Energy, January 2016, p. 41.

17 UNEP, “The Emissions Gap Report 2015," United Nations Environment Programme (2015).

18 A recent treatment of climate finance concerns in a bottom-up architecture, however, can be found in; Jonathan Pickering, Frank Jotzo, and Peter Wood, "Splitting the Difference: Can Limited Coordination Achieve a Fair Distribution of the Global Climate Financing Effort?” Global Environmental Politics 15, no. 4 (2015).

19 UNFCCC, "Decision 1/CP.20: Lima Call for Climate Action," FCCC/CP/2014/10/Add.1, February 2, 2015 .

${ }^{20}$ Cecilia Albin, "Negotiating International Cooperation: Global Public Goods and Fairness," Review of International Studies 29, no. 3 (2003).

${ }^{21}$ Notable exceptions were China and Canada.

${ }^{22}$ See also Andreas Lange et al., "On the Self-Interested Use of Equity in International Climate Negotiations," European Economic Review 54, no. 3 (2010).

${ }^{23}$ INDC Synthesis Report, p. 39. See also a discussion of the varying bases of fairness in Jonathan Pickering, Steve Vanderheiden, and Seumas Miller, "If Equity's In, We're Out': Scope for Fairness in the Next Climate Agreement," Ethics \& International Affairs 26, no. 4 (2012), pp. 423-43.

${ }^{24}$ INDC Synthesis Report, p. 38.

${ }^{25}$ For a comparative analysis of how fairness has been expressed in INDCs, see Kennedy Liti Mbeva and Pieter Pauw, "Self-Differentiation of Countries' Responsibilities: Addressing Climate Change Through Intended Nationally Determined Contributions," German Development Institute (DIE) Discussion Paper 4/2016.

${ }^{26}$ United States, "Intended Nationally Determined Contribution," March 31, 2015, www4.unfccc. int/submissions/INDC/Published\%2oDocuments/United\%20States\%20of\%20America/1/U.S. Cover Note INDC and Accompanying Information.pdf.

27 European Union, "Intended Nationally Determined Contribution of the EU and its Member States," March 6, 2015, www4.unfccc.int/submissions/INDC/Published\%2oDocuments/Latvia/1/LV-03-06EU\%2oINDC.pdf.

${ }^{28}$ South Africa, "South Africa's Intended Nationally Determined Contribution," September 25, 2015, www4. unfccc.int/submissions/INDC/Published\%2oDocuments/South\%2oAfrica/1/South\%2oAfrica.pdf. 
29 Australia, "Intended Nationally Determined Contribution to a new Climate Change Agreement," August 11, 2015, www4.unfccc.int/submissions/INDC/Published\%2oDocuments/Australia/1/ Australias\%2oIntended\%2oNationally\%2oDetermined\%2oContribution\%2oto\%20a\%2onew\%2oClimate\% 20Change\%2oAgreement\%20-\%20August\%202015.pdf.

${ }^{30}$ India, "India's Intended Nationally Determined Contribution," October 1, 2015, www4.unfccc. int/submissions/INDC/Published\%2oDocuments/India/1/INDIA\%2oINDC\%20TO\%2oUNFCCC.pdf.

${ }^{31}$ Bangladesh, "Intended Nationally Determined Contribution," September 25, 2015, www4.unfccc. int/submissions/INDC/Published\%2oDocuments/Bangladesh/1/INDC_2015_of_Bangladesh.pdf.

32 INDC Synthesis Report, p. 39.

33 Ibid., p. 59.

${ }^{34}$ Paris Agreement, Article 2.2. This formulation first emerged in the 2014 U.S.-Sino joint announcement, see The White House, 'US-China Joint Announcement on Climate Change', 11 November 2014, www. whitehouse.gov/the-press-office/2014/11/11/us-china-joint-announcement-climate-change.

${ }^{35}$ UNFCCC, Decision 1/CP.20.

${ }^{36}$ Paris Agreement, Article 4.3.

37 Proposals to conduct a formal, ex ante assessment of INDCs, including their equity dimensions, prior to the Paris conference failed to win consensus support at the preceding 2014 conference in Lima. See Hermann Ott et al., "Lima Climate Report: COP2o Moves at Snails' Pace on the Road to Paris," Wuppertal Institute for Climate, Environment and Energy, December 2014, p. 4. An African Group proposal for the Paris Agreement to include an "equity reference framework" also failed to win consensus, but see Xolisa Ngwadla, "An Operational Framework for Equity in the 2015 Agreement," Climate Policy 14, no. 1 (2014).

${ }^{38}$ ActionAid International et al., "Fair Shares: A Civil Society Equity Review of INDCs," October 2015, www.civilsocietyreview.org.

39 Alex Pashley, "Brazil Minister Calls Out Emerging Economies Over Weak Climate Pledges," October 28, 2015, www.climatechangenews.com/2015/10/28/brazil-minister-calls-out-emerging-economiesover-weak-climate-pledges/.

$4^{\circ}$ Alex Pashley, "Hall of Shame: Who Hasn't Pledged Yet to UN Climate Pact?' October 2, 2015, www. climatechangenews.com/2015/10/02/hall-of-shame-who-hasnt-pledged-yet-to-un-climate-pact/."

${ }^{41}$ See, for instance, Eliza Northrop and David Waskow, "INSIDER: How Transparent Have Countries Been About the Fairness and Ambition of Their National Climate Contributions (INDCs)?" August 25, 2015, www.wri.org/blog/2015/08/insider-how-transparent-have-countries-been-about-fairness-andambition-their-national.

42 Darrel Moellendorf, "Climate Change Justice," Philosophy Compass 10, no. 3 (2015); David Schlosberg, "Climate Justice and Capabilities: A Framework for Adaptation Policy," Ethics \& International Affairs 26, no. 4 (2012). 